STATE REPORTING OF LIVE NEWBORNS WEIGHING LESS THAN

$† 601500$ GRAMS AT BIRTH. Ann L. Wilson, Lawrence J. Fenton, Lawrence R. Wellman, University of South Dakota School of Lawrence $R$. Wellman,

In 1981 there was large variation in state reported incidence of live births of newborns weighing less than 500 grams at birth (.3 to 2.4 per 1,000 live births). The states with the lowest neonatal mortality rate (NMR) have the lowest incidence of birth weights less than 500 grams ( $r h o=.70$ ). Assuming that mortality for this weight category is $100 \%$, there is marked variation ( 5 to $24 \%$ ) in the contribution of this weight cohort to a state's tot NMR. Major deficiencies in reporting may exist. For example, Alaska, Arizona and North Dakota report no Native American births with weights less than 500 grams. Reporting may also depend on the definition of live birth. The American Academy of Pediatrics and American College of Obstetricians and Gynecologists Guidelines for Perinatal Care uses the World Health Organizat "irrespective of duration of pregnancy". Standard obstetric and pediatric textbooks offer guidance on this issue varying from adherence to the WHO definition to describing a live birth as greater than 500 grams. Thirty-six states officially use the WHO greater than solive birth and nine states have definitions without definition of gestational criteria. Four states have no definition of
birth including Vermont which has the nation's lowest NMR. There is evidence to suggest inconsistency in reporting the births of previable newborns which potentially affects national neonatal mortality statistics.

\section{THE EFFECT OF PRENATAL CARE UPON BIRTH WEIGHT-}

$\dagger 602$ SPECIFIC OUTCOME. Paul H. Wise. (Spon. by Jullus B. Polfcy Research and Education, Boston.

It is generally accepted that variations in birth weightspecific mortality rates (BWSMR) are closely related to the specife mort quality of medical care provided the neonate once
born. However, the effect of prenatal care on BWSMR has not been we11 explored. We studied linked birth/neonatal death vital welatistics files for the C1ty of Boston for the years 1975-79. Logistic models were used to assess the influence of prenatal care ad justing for race, gestational age, maternal age, education, and family income.

For the 329 deaths and 68,842 births analyzed, prenatal care was significantly related to overall neonatal survival $(p<.001)$

However, its effect upon BWSMR was not uniformly significant:

\begin{tabular}{|c|c|c|c|}
\hline & $\angle 1500 \mathrm{~g}$ & $1500-2500 \mathrm{~g}$ & $2500 \mathrm{~g}$ \\
\hline Adequ & 1.0 & 1.0 & 1.0 \\
\hline Inade & 1.3 & 1.1 & $1.5^{*}$ \\
\hline
\end{tabular}

${ }^{*} \mathrm{p}<.01$ renatal care does not great1y The data influence Bures a survival at prenatal care services appears to strongly accect to prenatal birth weights above $2500 \mathrm{~g}$. Alterations in access to prenatal care could therefore Influence both the distribution of low

RURAL VS. URBAN EPIDEMIOLOGY Robert. C. Woody, Charles M. Ginsburg. Arkansas Children's Hospital, Litt1 ock, and Children's Medical Center, Dallas, Dept. of Peds. a pucity of data is available on epidemiologic and clinical A paucity of data is avallable on epldemiologic and (C) characteristics of organophosphate (OP) and carbamate factors toxicity in children. To determine if epldemiologic factors influence the clinical course of these disorders, we compared
the exposure and hospital course of 25 children from a largely rural population (ACH) to 25 children from and urban area (CMC). Patients ranged 1n age from 1 mo to 11 yrs (mean age, 31 mos); 26 (52\%) were male. Thirty-six (72\%) of Intoxications occurred in the spring and summer. OP and C-containing products found in the home were the most common substances products found th causing toxicity in both groups. Although ch a result of rural areas were more commonly intoxicated as a result of agricultural spraying than urban children, accidental ingestion
of OP-containing products by infants (43\%) was the most common route in both groups. Passive exposure following home and agricultural spraying occured in $24 \%$ and $14 \%$ of patients, respectively. Twenty-four (48\%) of the agents were "over the counter" home insecticides; agricultural-use insecticides were counter hou in $22 \%$. The inftial clinical signs and symptoms and outcome did not relate to the route of exposure or and outcome dided. Urban children had a significantly larger substance ingested. $P=.001)$ and seizures $(P=.001)$ at the $t$ me of incidence of coma $(P=.001)$ and seizures $(P=.001)$ at hospital admission than did rural. The duration of
hospitalization and the type and incidence of complications did not differ between the two groups.
ROTAVIRUS: A DISEASE FOR ALL SEASONS IN ARKANSAS.

604 Terry Yamauchi,$\frac{\text { Rebecca Clarke, }}{\text { Ark. Med. Sc1 }}$ and Ark. Child. $\frac{\text { Sherr. Furr, Univ. }}{\text { Hosp., Department of }}$ Ark. Med. Sc1. and Ark.
Little Rock, Arkansas.

Pediatrics, Little Rock, Arkansas.
Rotavirus-assoctated gastroenteritis has been described as a Rotavirus-associated gastroenteritis has been descr
disease of infants. Previous studies from our institution demonstrated occurrence of rotavirus disease during summer months involving adults as well as infants. The purpose of this study was to document the incidence of rotavirus infection by month of the year. Rotazyme, a rapid diagnostic infection by month of the enzyme imnunoassay detection of test for the qualitative enzyme immunoassay detection of rotavirus antigen was utilized. Laboratory reports were
reviewed over a 12 month period. Rotavirus-positive fecal specimens were reported during every month of the year except April. Total numbers of rotazyme-positive patients were highest during January (14), and February (14). However, total fecal specimens analyzed were increased during those same months. During the months of May, June and July the ratio of rotavirus-positive stools to total numbers of submitted fecal specimens was greater. Carrier states were not considered in specimens was greater. Carrier states were not considysis. In this study and only symptomatic infal samples were recovered from symptomatic infants in every month of the year except Apri1; 2) h1ghest numbers of rotavirus positive specimens were found durtng January and February; 3) May, June and Ju1y had the higher ratios of rotavirus-positive stools to total numbers year round disease in Arkansas and may be a nore

605 EFFECT OF RIFAMPIN ON NASOPHARYNGEAL FLORA FOLLOWINC 605 PROPHYLAXIS FOR $H$. INFLUENZAE CARRIAGE. Ram Yogev and Kathy Kabat. Dept. of Pediatrics, Northwestern University Medical School, Children's Memorial Hosp., Chicago.

Rifampin (Rf) is currently recommended as prophylaxis for household and day-care center contacts of patients with $H$. influenzae invasive diseases. Rapid development of bacterial resistance $(R)$ to this drug is well-documented. Because Rf plays an important role in treatment of other conditions such as staphylococcal infections, streptococcal carriage, and $\mathrm{TB}$, we investigated the effect of Rf $20 \mathrm{mg} / \mathrm{kg}$ once a day for 4 days on the nasopharyngeal (NP) flora of 17 children. NP swabs were obtained before $\mathrm{Rf}$ prophylaxis and $48 \mathrm{hrs}$ post therapy. As shown in the before $\mathrm{R}$ propht laxiority Table, the vast majority of the isolates recovered before $\mathrm{kf}$. lated following Rf prophylaxis were Rf resistant (MIC $\geq 5 \mathrm{\mu g} / \mathrm{ml}$ ).

\begin{tabular}{|c|c|c|c|c|c|}
\hline Bacteria & & $\mathrm{Rf}$ & Afte & & de- \\
\hline Bacteria & $\bar{S}$ & D & $s$ & & velopment of Rf re- \\
\hline H. influenzae & & & & & flora in \\
\hline H. $i$ & 0 & 0 & 0 & 2 & opulation sug \\
\hline S. a & 5 & 0 & 1 & & gests the possible \\
\hline & 6 & 0 & 1 & & need to re-evaluate \\
\hline B. & 9 & 1 & 1 & & th prophylaxis \\
\hline Coagula & 6 & 1 & 0 & & recommendations \\
\hline Stre & 6 & 1 & & 15 & either to limit the \\
\hline Neisseria s & 4 & & 2 & & treated population \\
\hline Total & 43 & & 5 & $\overline{38}$ & add another \\
\hline
\end{tabular}

antibiotic in order to prevent emergence of $R$ strains.

\section{GASTROENTEROLOGY AND NUTRITION}

LACK OF CORRELATION BETWEEN SERUM VITAMIN E AND TOTAL

606 LIPID LEVELS IN PRETERM INFANTS. S. Abbasi, L. Johmson, J. Gerdes, C. Dalin, M. Grous, C. Otis, Univ. of Pa. Sch. of Med., Dept. of Peds,, Pennsylvania Hosp., Philadelphia. In adults and children there is a significant correliption (TL). Therofor of the serum ratio of $\mathrm{E}$ to TL (E/TL) as a measure The $\mathrm{E}$. This ratio may not be useful in infants because of the higher proporrate fin theirs order to evalution of polyunsaturated ate this relationship in neonates 34 . XGA 34.8wks \pm 2.1 SD were studied. Serum E and TL were measured during the following time periods: (I) within a few hours of birth; (II) 1 week of age, NPO, on hyperalimentation (HAL) and Thtralipid (IV) $1-2$ weeks

\begin{tabular}{|c|c|c|c|c|}
\hline 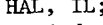 & & & & \\
\hline Period & $\mathrm{n}$ & $\underline{\overline{\mathrm{X}} \mathrm{E}(\mathrm{mg} / \mathrm{d} \mathrm{l}) \pm \mathrm{SD}}$ & $\underline{\overline{\mathrm{X}} \mathrm{TL}}(\mathrm{mg} / \mathrm{dl}) \pm \mathrm{SD}$ & $\mathrm{E} / \mathrm{TL}$ \\
\hline $\mathrm{I}$ & 70 & $0.6 \pm 0.2$ & $346 \pm 112$ & $\overline{1.75}$ \\
\hline II & 50 & $0.7 \pm 0.4$ & $388 \pm 158$ & 2.19 \\
\hline III & 34 & $1.2 \pm 0.6$ & $533 \pm 166$ & 2.34 \\
\hline. $\mathrm{IV}$ & 34 & $1.8 \pm 1.3$ & $432 \pm 137$ & 4.34 \\
\hline
\end{tabular}

Multiple measurements within each group showed a significant correlation between $\mathrm{E}$ and $\mathrm{TL}(\mathrm{r}=.43, \mathrm{p}<.01)$ only in period $\mathrm{I}$ and if all babies were considered. The $\mathrm{r}$ value however was only $0.4 \hat{\jmath}$ which reflects a relatively poor correlation. Af ter exogenous nutrition was started (periods II-IV), there was no correlation between $E$ and $T L(r=.02-.34)$ in any birthweight group. Serial measurements of serum vitamin $E$ levels appear to preterm neonate. 